\title{
Formal Education Versus Learning-by-Doing
}

\author{
Frédéric Gavrel $^{*}$ Isabelle Lebon ${ }^{\dagger} \quad$ Thérèse Rebière $^{\ddagger}$ \\ Preliminary Version
}

Janvier, 2009

\begin{abstract}
Our paper studies the efficiency of educational choices in a search-matching model where individuals face a tradeoff between acquiring formal education and learningby-doing while on-the-job. The labor market is hierarchically segmented into two sectors. When their educational effort is successful, (educated) workers can directly obtain a high-skill / better-paid job whereas when their effort is unsuccessful, uneducated workers have to go trough a low-skill job, learn by doing and then search while on-the-job for a high-skill job. We state that low-skill firms suffer from a hold up behavior by high-skill firms which create too many jobs. Job creation is thus suboptimal in the low-skill sector and individuals devote too much effort to formal education. A self-financed tax and subsidy policy restore market efficiency.
\end{abstract}

Keywords: Formal education; Learning-by-doing; Market efficiency; On-the-job search; Search unemployment.

JEL Codes: H21, I20, J21, J64.

${ }^{*}$ CERENE, Department of Economics, University of Le Havre, 25 rue Philippe Lebon, BP420, 76057 Le Havre cedex; frederic.gavrel@univ-lehavre.fr

${ }^{\dagger}$ CERENE, Department of Economics, University of Le Havre, 25 rue Philippe Lebon, BP420, 76057 Le Havre cedex; isabelle.lebon@univ-lehavre.fr

${ }^{\ddagger}$ Corresponding author; CERENE, Department of Economics, University of Le Havre, 25 rue Philippe Lebon, BP420, 76057 Le Havre cedex; phone: +33(0)2 327441 21; fax: +33(0)2 327440 86; therese.rebiere@univ-lehavre.fr 


\section{Introduction}

Formal education is not the only way to acquire the skills which provide workers with the opportunity of holding a good job. Learning-by-doing in a low-skill job and then searching (while on-the-job) for a high-skill job is another way. Do workers choose the right amount of formal education when faced to this tradeoff? And if not, what public policy should be implemented?

Although human capital is generally measured by the amount of formal education, many skills are best learned on the job thanks to participation in the production process, i.e. learning-by-doing (see Arrow (1962)). In this sense, training also determines workers productivity. Acquiring human capital can be thus achieved thanks to educational choices between formal education (schooling, apprenticeship) and/or training (see Becker 1975). The former is achieved before the worker finds a job whereas the latter is acquired on the job either by learning-by-doing or on-the-job training.

During the past decades, more and more individuals have chosen to reinforce the intensity of their formal education effort. This well-known phenomenon has been, among others, reported by Machin (1994) who stated the existence of an increase in the relative use of skilled labor and an increase in the relative share of graduates in the UK in the 1980s. Acemoglu (2002) summed up the same empirical evidences for the US where a large increase occurred in the supply of more educated workers the last sixty years, this rise being stronger in the 1970s. Mincer $(1994,2003)$ reported a levelling off in the 1980s, when the demand accelerated, followed by an increase in the relative supplies of educated workers in the 1990s. Moscarini and Vella (2008) witnessed this trend using the Current Population Survey from 1979 to 2004, outlining the increase in the High-School graduates until mid-1990's and the ongoing rise in the proportion of College graduates.

Did those private educational choices lead to an efficient outcome? The purpose of this paper is to shed some light on this issue. We argue that individuals tend to put too much emphasis on formal education relative to training in the workplace. The reason for this does not lie on the educational decisions by themselves. This distortion comes from the fact that firms with high-skill jobs underestimate the social cost of filling their vacancies with workers coming from low-skill jobs in which they have learned by doing. Firms create too much high-skill jobs. In response to this hold up behavior, job creation is suboptimal in the low-skill sub-market. As a result high-skill jobs are too appealing and individuals' formal educational effort is too strong. This create some motivation for levying a tax on the output of high-skill firms.

To assess the consistency of our argument, we use a search matching model (Pissarides (2000)) with static Nash bargaining and free-entry. The labor market is segmented into two sub-markets. In sub-market 1, firms offer high-skill (better-paid) jobs whereas firms from sector 2 supply low-skill (lower-paid) jobs. When holding a low-skill job, a worker receive a lower wage but after having learned by doing, she can search (on the job) for a high-skill job, earning then a higher wage when finding one. New workers first decide on their formal education effort. If they succeed in acquiring the required skills, they directly 
join the pool of applicants for good jobs. If they fail, they have to search for a low-skill job and they begin to learn on-the-job. When the learning-by-doing process comes to its end, workers are endowed with the same skills as (formally) educated workers. They then can join the pool of applicants for good jobs.

First, we describe a (decentralized) stationary equilibrium of the labor market. One salient feature of such an equilibrium is that it is recursive in terms of market tightness and educational effort. We then study the welfare properties of such a decentralized equilibrium, assuming that firms internalize the well-known congestion effect (Hosios (1990), Pissarides (2000)). In a first step, we prove that high-skill job creation is too high. But, to the contrary, low-skill job creation as well as individuals' educational choices are partially efficient. In other words, they are optimal for the equilibrium value of the tightness of the high-skill labor sub-market. This means that, in line with our intuition, the inefficiency entirely comes from an excessive creation of high-skill vacancies. In a second step, we compare the decentralized equilibrium with a social optimum. The results validate the consistency of our argument: low skill jobs are too few and individuals put too much emphasis on formal education.

Next, we show that a Tax and Subsidy Policy (TSP) can decentralize the social optimum. Taxes must be levied on (filled) good jobs. They make that the perceived hiring costs coincide with the social ones. However, these taxes distort low-skill job creation as well as educational choices. In order to restore market efficiency, these taxes must be dedicated to the funding of two kinds of compensatory transfers. One is allocated to the firms of the low-skill sub-market when they loose their workers who quit them for a better job. The other one is a reward that workers receive if their formal education is successful. The reason why rewarding the laureates is necessary is that taxes which have to be levied on high-skill jobs lower the surplus of a match with such jobs, hence the return to formal education for workers.

Economists have been interested in the efficiency of human capital investment for a long time. A controversial issue, going back to Pigou (1912), is the one of governmental involvement aiming at increasing skills. As firms would not have any interest in investing in workers' skills because of the risk that their newly trained workers quit for external opportunities, government subsidies seemed to be a necessary measure for improving training as well as schooling. By opposition, Becker (1964) pointed out that the solution for human capital inefficiency may be better loan markets rather than government regulation and training subsidies. A competitive labor market implies that workers are the only ones incentivized to invest in their general training, bearing the cost either directly out of their pocket or by taking a wage cut. Therefore, unless workers are credit constrained, the right amount of investment for the market to be efficient would be undertaken.

More recently, labor theory reexamined the issue of educational choice in the presence of market imperfections. Our paper is a contribution to this literature. In their survey about non-competitive theories of training, Acemoglu and Pischke (1999) argued that labor market imperfections such as search frictions allow to account for employer-provided on-the-job training because firms are able to recoup their investment in human capital. 
Moen (1999) studies the efficiency of educational choices when workers compete for jobs. Charlot and Decreuze (2007) modelled a 2-schooling levels / 2 sectors labor market in which budget constrained workers, differing with respect to labor market ability, self-select their educational choice (see also Charlot and Decreuze (2005)). The ability differentiation of workers is also explored by Lechthaler and Snower (2007) who analyzed the interaction of institutional variables in determining employer-provided training. The previous papers did not take the on-the-job search process into account. We argue that the on-the-job search process change the efficiency results. When low-skill workers search while onthe-job in order to get a better paid job, the efficiency of the labor market requires a governmental intervention.

In order to set up public policies leading workers to get an efficient amount of skills, economists investigated several forms of educational process. In this way Heckman, Lochner and Cossa (2002) investigated the impact of wage subsidies on skill formation by distinguishing two models of training: a learning-by-doing model where skills are acquired as a by-product of work, and an on-the-job training model where investing in training is rival with working ${ }^{1}$, as in Becker (1964) or Ben Porath (1967). They state that contrary to on-the-job training models, learning-by-doing models predict that wage subsidies increase skill formation. Their estimation of the impact of the Earned Income Tax Credit (refundable tax credit) on skill formation shows that this tax reduced the long term wages of participants with low levels of education. The impact of some public policies on educational choices have recently been highlighted by Adda et al. (2006) who considered a model with formal education and on-the-job training. To the contrary, our contribution emphasizes the opposition between formal education and learning-by-doing.

The paper is organized as follows. Section 2 outlines our the analytical framework. We define a labor market decentralized (stationary) equilibrium in section 3. Section 4 studies market efficiency and states two main results: a decentralized equilibrium is partially efficient in terms of low-skill job creation and educational choices but inefficient in terms of high-skill job creation; the laissez-faire situation is inefficient. In section 5, we exhibit a self-financed fiscal policy which rewards educational success and leads to a social optimum. Finally, section 6 contains some concluding comments.

\section{Analytical framework}

The economy consists of two types of agents, workers and firms. Firms are infinity-lived whereas workers have a finite life expectancy of $1 / \mathrm{m}$. Time is continuous and parameter $m$ measures workers' labor market exit rate. Each worker who leaves the market is replaced with a newcomer. The measure of the total labor force is constant and normalized to one. All agents are risk-neutral and discount future payoffs at rate $r(r \geq 0)$.

The labor market is segmented into two interacting sub-markets (sectors arranged into

\footnotetext{
${ }^{1}$ see Killingsworth (1982) for a theoretical comparison of those models and the framework for a joint training-learning model as alternative forms of human capital accumulation.
} 
a hierarchy). Sector 2 offers low-skill jobs, while sector 1 offers high-skill jobs. Workers decide on their formal education effort $e$ such that when entering the labor market, workers with successful effort will enter the pool of applicants for high-skill jobs (high-skill unemployment), whereas workers with unsuccessful effort will enter the pool of applicants for low-skill jobs. Workers with low-skill jobs will therefore have to engage a learning-bydoing process in order to become skill enough to be employable in a high-skill firm. The expected duration of this process is denoted by $(1 / \lambda)$. workers thus acquire the required skills at Poisson rate $\lambda$. When the learning process comes to an end, workers engage in an on-the-job search process, hoping to get a high-skill job. The incentive to look for a high-skill job is the wage differentiation between sectors.

When entering the labor market, firms choose the sub-market $i(i=1,2)$ in which they will operate. They then create a single job in their chosen sub-market. Frictions exist that prevent the instantaneous matching of jobs with workers. Firms thus have to pay a cost, $c$, in order to keep their vacancy open. When matched with a worker, jobs yield output $y_{1}$ in sector $1, \hat{y}_{2}$ in sector 2 when workers are trained and $y_{2}$ when workers are untrained (with $y_{1}>\hat{y}_{2}>y_{2}$. Wages are negotiated. Workers have a bargaining power of $\beta$ and firms have a bargaining power of $(1-\beta)$. Sector 1 offers $w_{1}$ whereas sector 2 offers $w_{2}$ when workers are untrained and $\hat{w}_{2}$ when workers had learned by doing, where $w_{1}>\hat{w}_{2}>w_{2}$.

Job creation results from the usual assumption of free entry in both sectors. Market frictions in sector- $i$ are summarized in a constant-returns matching function that defines the arrival rate of workers to job vacancies $q_{i}\left(\theta_{i}\right)$ with $q_{i}^{\prime}\left(\theta_{i}\right)<0$ and the arrival rate of job offers to searching workers $p_{i}=\theta_{i} q_{i}$ with $p_{i}^{\prime}\left(\theta_{i}\right)>0$, where $\theta_{i}$ is the sub-market tightness.

\subsection{High-skill jobs}

\subsubsection{Asset values}

In sub-market 1 , the lifetime utility of an employed worker, called $W_{1}$, satisfies:

$$
(r+m)\left(W_{1}-U_{1}\right)=w_{1}-(r+m) U_{1}
$$

where $w_{1}$ denotes workers' wage and $U_{1}$ is the lifetime utility of a high-skill worker when unemployed. We have:

$$
(r+m) U_{1}=d+p_{1}\left(W_{1}-U_{1}\right)
$$

with $d$ being the value of leisure.

Regarding sector 1 firms, the value of a filled job, called $J_{1}$, verifies:

$$
(r+m)\left(J_{1}-V_{1}\right)=y_{1}-w_{1}-(r+m) V_{1}
$$

where $V_{1}$ is the asset value of a sector 1 firm whose job is vacant. We have:

$$
r V_{1}=-c+q_{1}\left(J_{1}-V_{1}\right)
$$




\subsubsection{Private surplus and market tightness}

When a worker and a firm meet and agree to form a match, the private surplus form this match is shared between them such as $S_{1}=\left[W_{1}-U_{1}\right]+\left[J_{1}-V_{1}\right]$. From equations (1) and (3), we deduce that the (private) surplus of a match in sub-market $1, S_{1}$, satisfies:

$$
(r+m) S_{1}=y_{1}-(r+m)\left(U_{1}+V_{1}\right)
$$

As the wage $w_{1}$ stems from static Nash bargaining, we have:

$$
\beta S_{1}=\left[W_{1}-U_{1}\right]
$$

We thus obtain:

$$
\left(r+m+\beta p_{1}\left(\theta_{1}\right)\right) S_{1}=y_{1}-d-(r+m) V_{1}
$$

As already mentioned, in both sub-markets, job creation results from the assumption of free-entry $\left(V_{1}=0\right)$. We thus have:

$$
\left(r+m+\beta p_{1}\left(\theta_{1}\right)\right) S_{1}=y_{1}-d
$$

Consequently, by using (4), the market tightness $\theta_{1}$ is determined by the following equilibrium equation:

$$
-c+q_{1}\left(\theta_{1}\right)(1-\beta) S_{1}=0
$$

This equilibrium equation is equivalent to the reduced form of the basic matching model (Pissarides (2000)). So, an increase in parameters $c, \beta, d, r$ and $m$ lowers the market tightness $\theta_{1}$ whereas an increase in the output $y_{1}$ stimulates job creation in this submarket.

\subsection{Low-skill jobs}

\subsubsection{Asset values}

When the training period comes to its end, the output of a worker in a low-skill job raises from $y_{2}$ to $\hat{y}_{2}$ and the worker begins to search (while on the job) for a high-skill vacancy. Her outside opportunities are defined by the lifetime utility of an unemployed worker in sub-market 1 (utility $U_{1}$ ). As Nash bargaining is static, the wage jumps from $w_{2}$ to $\hat{w}_{2}$. It means that we first need to define asset values associated with a match between a low-skill job and a trained worker) (hereafter referred to as an on-the-job seeker). So let $\hat{W}_{2}$ be the lifetime utility of such a worker. Using (6), one can show that this asset value satisfies:

$$
\left(r+m+p_{1}\right)\left(\hat{W}_{2}-U_{1}\right)=\hat{w}_{2}+p_{1} \beta S_{1}-(r+m) U_{1}
$$

Regarding sector 2 firms, the value of a low-skill job when matched with an on-the-job seeker, called $\hat{J}_{2}$, verifies: 


$$
\left(r+m+p_{1}\right)\left(\hat{J}_{2}-V_{2}\right)=\hat{y}_{2}-\hat{w}_{2}-r V_{2}
$$

where $V_{2}$ is the value of a sector 2 vacancy.

From equations (9) and (10), we deduce that the (private) surplus of a match of a sector 2 firm with an on-the-job-seeker, $\hat{S}_{2}$. Knowing that $\hat{S}_{2}=\left[\hat{W}_{2}-U_{1}\right]+\left[\hat{J}_{2}-V_{2}\right]$, the private surplus $\hat{S}_{2}$ satisfies:

$$
\left(r+m+p_{1}\right) \hat{S}_{2}=\hat{y}_{2}+p_{1} \beta S_{1}-(r+m) U_{1}-r V_{2}
$$

Under the assumption of free-entry $\left(V_{2}=0\right)$, the substitution of (2) into (11) yields:

$$
\left(r+m+p_{1}\left(\theta_{1}\right)\right) \hat{S}_{2}=\hat{y}_{2}-d
$$

We can now define the asset values associated with a match of a sector 2 firm and newcomer in sub-market 2.

As Nash bargaining implies that:

$$
\hat{W}_{2}-U_{1}=\beta \hat{S}_{2}
$$

we obtain that the lifetime utility of an unskilled worker when holding a sector 2 job, $W_{2}$, satisfies:

$$
(r+m+\lambda)\left(W_{2}-U_{2}\right)=w_{2}+\lambda \beta \hat{S}_{2}+\lambda U_{1}-(r+m+\lambda) U_{2}
$$

where $U_{2}$ is the value of unemployment in this sub-market. We have:

$$
(r+m) U_{2}=d+p_{2}\left(W_{2}-U_{2}\right)
$$

On the firms' side, the value of a job when held by a newcomer verifies:

$$
r J_{2}=y_{2}-w_{2}-m\left(J_{2}-V_{2}\right)+\lambda\left(\hat{J}_{2}-J_{2}\right)
$$

Under the assumptions of free-entry $\left(V_{2}=0\right)$ and Nash bargaining, the latter equation can be rewritten as:

$$
(r+m+\lambda) J_{2}=y_{2}-w_{2}+\lambda(1-\beta) \hat{S}_{2}
$$

\subsubsection{Private surplus and market tightness}

The private surplus of an untrained worker matched with a sector 2 firm is such that $S_{2}=\left[W_{2}-U_{2}\right]\left[J_{2}-V_{2}\right]$. From equations (13) and (16), we deduce $S_{2}$ as a function of $\hat{S}_{2}$ :

$$
(r+m+\lambda) S_{2}=y_{2}+\lambda \hat{S}_{2}+\lambda U_{1}-(r+m+\lambda) U_{2}
$$

Finally, by using (2) and (14), one can see that equation (17) can be rewritten as follows:

$$
\frac{(r+m+\lambda)\left(r+m+\beta p_{2}\left(\theta_{2}\right)\right)}{r+m} S_{2}=y_{2}+\lambda \hat{S}_{2}-d+\frac{\lambda}{r+m} \beta p_{1}\left(\theta_{1}\right) S_{1}
$$


As a result, the assumption of free-entry determines the market tightness $\theta_{2}$ by the following equilibrium equation:

$$
-c+q_{2}(1-\beta) S_{2}=0
$$

where the cost to keep a vacancy open, $c$, is assumed to be same in both sub-markets.

\section{$2.3 \quad$ Educational choices}

When entering the labor market, a new worker decide on her formal education effort. Her effort, denoted by $e$, determines the probability $\pi$ for becoming a high-skill worker. If she succeeds, she enters the pool of applicants for high-skill jobs; if she fails, she must search for a low-skill jobs and begins a learning-by-doing process when finding one. The probability $\pi$ is assumed to be an increasing and concave function $\pi(e)$ of the effort $e$ $\left(\pi^{\prime}()>0,. \pi^{\prime \prime}()<0.\right)$.

The education effort is then obtained by maximizing the following objective:

$$
E D \equiv-e+\pi(e) U_{1}+(1-\pi(e)) U_{2}
$$

We obtain the following first order condition:

$$
\pi^{\prime}(e)\left(U_{1}-U_{2}\right)-1=0
$$

For obvious reasons, the effort $e$ increases with the difference $\left(U_{1}-U_{2}\right)$. From the concavity of function $\pi($.$) , we deduce that the second order condition is satisfied.$

Using equations (2) and (14), we can rewrite the optimality condition as follows:

$$
\pi^{\prime}(e) \beta\left(p_{1} S_{1}-p_{2} S_{2}\right)-(r+m)=0
$$

The educational effort is an increasing function of the private surplus $S_{1}$ whereas it is a deceasing function of the private surplus $S_{2}$. In other words, workers would have an incentive to increase (reduce) their educational effort is the gain of holding a high-skill (low-skill) job increase.

\section{Equilibrium}

\subsection{Definition}

In sum, an equilibrium of the labor market can be defined as follows:

Definition 1. An equilibrium of the labor market is a set of variables $\left(S_{1}, \theta_{1}, \hat{S}_{2}, S_{2}, \theta_{2}, e\right)$ which jointly satisfy equations (7), (8), (12), (18), (19) and (22).

From market tightness and the probability $\pi$, one deduces the employment and unemployment levels in both sub-markets by using the conditions for flow-equilibrium. 


\subsection{Employment and unemployment levels}

In steady state, employment and unemployment levels are deduced from the flow-equilibrium conditions. All employment (unemployment) variables are divided by the total labor force. In sub-market 1 , high-skill unemployment $u_{1}$ and high-skill employment $l_{1}$ are obtained from the following equations:

$$
\begin{aligned}
& m \pi=\left(m+p_{1}\right) u_{1} \\
& m l_{1}=p_{1}\left(u_{1}+\hat{l}_{2}\right)
\end{aligned}
$$

where $\hat{l}_{2}$ is the number of on-the-job seekers (i.e. the level of high-skill employment in sub-market 2).

In sub-market 2 , low-skill unemployment $u_{2}$, low-skill employment $l_{2}$ and high-skill employment $\hat{l}_{2}$ are derived from the following conditions:

$$
\begin{gathered}
m(1-\pi)=\left(m+p_{2}\right) u_{2} \\
m l_{2}+\lambda l_{2}=p_{2} u_{2} \\
\left(m+p_{1}\right) \hat{l}_{2}=\lambda l_{2}
\end{gathered}
$$

$v_{i}$ denoting vacant jobs in the labor sub-market $i$, the sub-market tightness of sector 1 is given by $\theta_{1}=v_{1} /\left(u_{1}+\widehat{\ell}_{2}\right)$ and the sub-market tightness of sector 2 is given by $\theta_{2}=v_{2} / u_{2}$. From these flow-equilibrium conditions, we derive the impacts of variables $\theta_{1}, \theta_{2}$ and $\pi$ on all employment and unemployment levels. Table 1 reports these partial derivatives. The variable $\eta_{i}(i=1,2)$ denotes the elasticity of rate $q_{i}$ with respect to market tightness $\theta_{i}$ (in absolute value).

Table 1: partial derivatives of employment and unemployment levels

\begin{tabular}{|c|c|c|}
\hline & $u_{2}$ & $l_{2}$ \\
\hline$\theta_{1}$ & 0 & 0 \\
\hline$\theta_{2}$ & $-\frac{m(1-\pi) q_{2}\left(1-\eta_{2}\right)}{\left(m+p_{2}\right)^{2}}$ & $\frac{m^{2}(1-\pi) q_{2}\left(1-\eta_{2}\right)}{(m+\lambda)\left(m+p_{2}\right)^{2}}$ \\
\hline$\pi$ & $-\frac{m}{m+p_{2}}$ & $-\frac{m p_{2}}{(m+\lambda)\left(m+p_{2}\right)}$ \\
\hline
\end{tabular}

\begin{tabular}{|c|c|c|c|}
\hline & $\hat{l}_{2}$ & $u_{1}$ & $l_{1}$ \\
\hline$\theta_{1}$ & $-\frac{\lambda l_{2} q_{1}\left(1-\eta_{1}\right)}{\left(m+p_{1}\right)^{2}}$ & $-\frac{m \pi q_{1}\left(1-\eta_{1}\right)}{\left(m+p_{1}\right)^{2}}$ & $\frac{\left(u_{1}+\hat{l}_{2}\right) q_{1}\left(1-\eta_{1}\right)}{m+p_{1}}$ \\
\hline$\theta_{2}$ & $\frac{\lambda}{m+p_{1}} \frac{\partial l_{2}}{\partial \theta_{2}}$ & 0 & $\frac{\lambda p_{1}}{m\left(m+p_{1}\right)} \frac{\partial l_{2}}{\partial \theta_{2}}$ \\
\hline$\pi$ & $-\frac{\lambda m p_{2}}{\left(m+p_{1}\right)(m+\lambda)\left(m+p_{2}\right)}$ & $\frac{m}{m+p_{1}}$ & $\frac{p_{1}}{m+p_{1}}+\frac{p_{1}}{m} \frac{\partial \hat{l}_{2}}{\partial \pi}$ \\
\hline
\end{tabular}




\section{Efficiency}

We now study the welfare properties of a decentralized equilibrium (Definition 1). As firms do not internalize the social cost of hiring a high-skill worker coming from the lowskill sector, the creation of high-skill jobs appears to be too high. Due to this hold up phenomenon, job creation is suboptimal in the low-skill sub-market. As a consequence, educational choices are inefficient; workers devote too much effort to formal education.

Along the same line as Hosios (1990) and Pissarides (2000), let us consider a social planner who is only subject to search frictions and can redistribute income at no cost. In this case, the efficiency criterion is the social surplus. For the sake of expositional simplicity, the interest rate $r$ is assumed to be equal to zero ${ }^{2}$. This assumption allows us to compare steady states according to the social surplus per period.

Denoted by $\Sigma$, the social surplus per head and per period is given by:

$$
\Sigma=l_{1} y_{1}+l_{2} y_{2}+\hat{l}_{2} \hat{y}_{2}+\left(u_{1}+u_{2}\right) d-\theta_{1}\left(u_{1}+\hat{l}_{2}\right) c-\theta_{2} u_{2} c-m e
$$

In what follows, for methodological reasons, we will also assume that the usual Hosios' condition holds true in both sub-markets, that is:

$$
\eta_{1}=\eta_{2}=\beta
$$

\subsection{High-skill job creation}

Let us first study the efficiency of the creation of high-skill jobs. Using Table 1, one can show that the derivative of the surplus $\Sigma$ with respect to $\theta_{1}$ has the same sign as:

$$
H S \equiv\left(1-\eta_{1}\right) q_{1}\left[y_{1}-\left(\frac{\hat{l}_{2}}{u_{1}+\hat{l}_{2}} \hat{y}_{2}+\frac{u_{1}}{u_{1}+\hat{l}_{2}} d\right)\right]-\left(m+\eta_{1} p_{1}\right) c
$$

As:

$$
\frac{\hat{l}_{2}}{u_{1}+\hat{l}_{2}} \hat{y}_{2}+\frac{u_{1}}{u_{1}+\hat{l}_{2}} d>d
$$

it results that firms create too many vacancies in a decentralized equilibrium (see equation (8)). The intuition behind this result is that with static Nash bargaining, firms underestimate the (social) opportunity cost of a match with a worker who comes from sub-market 2 . This cost is given by the output $\hat{y}_{2}$ which is higher than the value of leisure. As a consequence, job creation in sub-market 1 is all the more inefficient as the share of on-the-job seekers in the pool of applicants for a high-skill job is large. In other words, firms of sub-market 2 suffer from a hold up behavior of firms of sub-market 1 .

\footnotetext{
${ }^{2}$ Main results extend to a positive interest rate
} 


\subsection{Low-skill job creation}

One can show that the derivative of the social surplus $\Sigma$ with respect to the market tightness $\theta_{2}$ has the same sign as ${ }^{3}$ :

$$
\begin{aligned}
L S \equiv \quad & \left(1-\eta_{2}\right) q_{2} \frac{\lambda}{m\left(m+p_{1}\right)}\left[p_{1}\left(y_{1}-d\right)-m \theta_{1} c\right] \\
& +\left(1-\eta_{2}\right) q_{2}\left[y_{2}-d+\frac{\lambda\left(\hat{y}_{2}-d\right)}{m+p_{1}}\right]-\frac{(m+\lambda)\left(m+\eta_{2} p_{2}\right)}{m} c
\end{aligned}
$$

We shall state that $L S$ is equal to zero in a decentralized equilibrium (Definition 1 ). This means that the equilibrium value of the sub-market tightness $\theta_{2}$ is partially efficient. In other words, it is socially optimal for a given level of variables $\theta_{1}$ and $e$.

To that aim, let us consider the expression:

$$
X \equiv p_{1}\left(y_{1}-d\right)-m \theta_{1} c
$$

For a nil interest rate, this expression can be rewritten as follows (see equation (7)):

$$
X=p_{1}\left(m+\beta p_{1}\right) S_{1}-m \theta_{1} c
$$

Now, according to the equilibrium equation (8), we have:

$$
m \theta_{1} c=m(1-\beta) p_{1} S_{1}
$$

Substitution into $X$ then yields:

$$
X=\left(m+p_{1}\right) \beta p_{1} S_{1}
$$

Under the Hosios' condition, this proves that the derivative of the social surplus with respect to the sub-market tightness $\theta_{2}$ is zero in a decentralized equilibrium (see the equilibrium equation (19)).

At first glance, this (partial) efficiency result might look surprising as, via on-the-job search, employment in high-skill jobs depends positively on low-skill job creation (see Table 1). But private surplus $S_{2}$ takes this externality in account through the term $\beta p_{1} S_{1}$ (see equation (19)). In words, holding a low-skill job gives workers the opportunity of getting a high-skill one. It raises the workers' surplus for a given wage. Assuming Nash bargaining, the firms' surplus rises as well, thus stimulating low-skill job creation.

\subsection{Educational choices}

One can check ${ }^{4}$ that, for a nil interest rate, the derivative of the social surplus with respect to the formal education effort has the same sign as:

\footnotetext{
${ }^{3}$ Detailed calculus are available upon request from the authors.

4 idem
} 


$$
\begin{aligned}
E \equiv \quad & {\left[1-\frac{\lambda p_{2}}{(m+\lambda)\left(m+p_{2}\right)}\right]\left[\frac{p_{1}\left(y_{1}-d\right)}{m+p_{1}}-\frac{m \theta_{1} c}{m+p_{1}}\right] } \\
& -\frac{m}{m+\lambda}\left[\frac{p_{2}}{m+p_{2}}\left(y_{2}-d+\lambda \hat{S}_{2}\right)-\frac{m+\lambda}{m+p_{2}} \theta_{2} c\right]-\frac{m}{\pi^{\prime}(e)}
\end{aligned}
$$

Here also, we shall state that $E$ is equal to zero in a decentralized equilibrium. In other words, the educational effort $e$ appears to be partially efficient.

For this purpose, let us first consider the quantity $\beta p_{1} S_{1}$. From the definition of the private surplus $S_{1}$ (see equation (7)), we deduce (for $r=0$ ):

$$
\beta p_{1} S_{1}=\frac{p_{1}}{m+p_{1}}\left(y_{1}-d\right)+\frac{m}{m+p_{1}}\left(y_{1}-d\right)-m S_{1}
$$

By using the equilibrium equation (8), we obtain:

$$
\frac{m}{m+p_{1}}\left(y_{1}-d\right)-m S_{1}=-\frac{m}{m+p_{1}} p_{1}(1-\beta) S_{1}=-\frac{m}{m+p_{1}} \theta_{1} c
$$

It results that:

$$
\frac{p_{1}}{m+p_{1}}\left(y_{1}-d\right)-\frac{m}{m+p_{1}} \theta_{1} c=\beta p_{1} S_{1}
$$

Substitution of equation (32) into equation (31) then yields:

$$
E=\beta p_{1} S_{1}-\frac{m}{m+\lambda}\left[\frac{p_{2}}{m+p_{2}}\left(y_{2}-d+\lambda \hat{S}_{2}+\frac{\lambda \beta p_{1} S_{1}}{m}\right)-\frac{m+\lambda}{m+p_{2}} \theta_{2} c\right]-\frac{m}{\pi^{\prime}(e)}
$$

Let us now consider the quantity $\beta p_{2} S_{2}$. From the definition of the private surplus $S_{2}$ (see equation (18)), we deduce (for $r=0$ ):

$$
\frac{m+\lambda}{m} \beta p_{2} S_{2}=y_{2}-d+\lambda \hat{S}_{2}+\frac{\lambda \beta p_{1} S_{1}}{m}-(m+\lambda) S_{2}
$$

The latter equation can be rewritten as follows:

$$
\begin{aligned}
\frac{m+\lambda}{m} \beta p_{2} S_{2}= & \frac{p_{2}}{m+p_{2}}\left[y_{2}-d+\lambda \hat{S}_{2}+\frac{\lambda \beta p_{1} S_{1}}{m}\right] \\
& +\frac{m}{m+p_{2}}\left[y_{2}-d+\lambda \hat{S}_{2}+\frac{\lambda \beta p_{1} S_{1}}{m}\right]-(m+\lambda) S_{2}
\end{aligned}
$$

By using the equilibrium equation (19), we obtain:

$$
\begin{aligned}
\frac{m}{m+p_{2}}\left[y_{2}-d+\lambda \hat{S}_{2}+\frac{\lambda \beta p_{1} S_{1}}{m}\right]-(m+\lambda) S_{2} & =\frac{m+\lambda}{m+p_{2}}\left(m+\beta p_{2}\right) S_{2}-(m+\lambda) S_{2} \\
& =-\frac{m+\lambda}{m+p_{2}} p_{2}(1-\beta) S_{2}=-\frac{m+\lambda}{m+p_{2}} \theta_{2} c
\end{aligned}
$$


We thus have:

$$
\frac{p_{2}}{m+p_{2}}\left[y_{2}-d+\lambda \hat{S}_{2}+\frac{\lambda \beta p_{1} S_{1}}{m}\right]-\frac{m+\lambda}{m+p_{2}} \theta_{2} c=\frac{m+\lambda}{m} \beta p_{2} S_{2}
$$

Substitution of (34) into (33) finally yields:

$$
E=\beta p_{1} S_{1}-\beta p_{2} S_{2}-\frac{m}{\pi^{\prime}(e)}
$$

This shows that, in a decentralized equilibrium, the derivative of the social surplus with respect to the educational effort $e$ is nil (see equilibrium equation (22)). Notice that the Hosios' condition was not used in stating this point. Furthermore this result remains true whatever the value of workers' bargaining strength $\beta$ is.

The following proposition summarizes these (partial) efficiency results:

Proposition 1. A decentralized equilibrium of the labor market is partially efficient in terms of low-skill job creation $\left(\theta_{2}\right)$ and educational effort (e) but inefficient in terms of high-skill job creation $\left(\theta_{1}\right)$.

It is worth noting that the efficiency of market tightness $\theta_{2}$ is very partial as it only holds for the (decentralized) equilibrium value of market tightness $\theta_{1}$. However, one can check that in the absence of on-the-job search, a decentralized equilibrium would coincide with a social optimum (under the Hosios' condition).

\subsection{Social optimum and decentralized equilibrium}

A social optimum can be defined as follows:

Definition 2. A social optimum is a set of variables $\left(\theta_{1}, \theta_{2}, e\right)$ which jointly satisfy $H S=$ $L S=E=0$.

The partial efficiency results we stated above are interesting in themselves as they enable us to understand why the decentralized equilibrium (Definition 1 ) is not a social optimum (Definition 2). We now use them to see how a decentralized equilibrium is located relative to a social optimum. We already know that job creation is beyond its optimal level in the high-skill sector. Market tightness $\theta_{1}$ is too high. What can be said about job creation in the low-skill sub-market and the educational effort of entrant workers? Under the Hosios' condition, we state the following proposition:

Proposition 2. Relative to a social optimum, the low-skill job creation $\left(\theta_{2}\right)$ is too low in a decentralized equilibrium. As a consequence, individuals' education effort $(e)$ is too high.

Proof We first prove that $\theta_{2}$ is too low. To that end, let us consider the following system of two equations in $\left(\theta_{1}, \theta_{2}\right)\left(\eta_{1}=\eta_{2}=\eta\right)$ : 


$$
\begin{gathered}
(1-\eta) q_{1}\left[y_{1}-d-\alpha\left(\hat{y}_{2}-d\right)\right]-\left(m+\eta p_{1}\right) c=0 \\
0=\quad q_{2}(1-\eta)\left(y_{2}-d\right)-\frac{m+\lambda}{m} c \eta p_{2}-(m+\lambda) c \\
+q_{2}(1-\eta) \frac{\lambda}{m}\left[\frac{p_{1}}{m+p_{1}}\left(y_{1}-d\right)+\frac{m}{m+p_{1}}\left(\hat{y}_{2}-d\right)-\frac{m}{m+p_{1}} \theta_{1} c\right]
\end{gathered}
$$

where the parameter $\alpha$ takes its values from the range $\left[0, \alpha^{*}\right]$. The bound $\alpha^{*}$ is the value of the ratio $\frac{\hat{l}_{2}}{u_{1}+\hat{l}_{2}}$ in a social optimum. Equation (36) is obtained by equalizing $L S$ to zero (see equation (30)).

For $\alpha=0$, the previous equations depicts a decentralized equilibrium whereas they define a social optimum for $\alpha=\alpha^{*}$. One can see that the first equation determines $\theta_{1}$ as a decreasing function of $\alpha$.

Let $H$ be the following expression:

$$
H \equiv \frac{p_{1}}{m+p_{1}}\left(y_{1}-d\right)+\frac{m}{m+p_{1}}\left(\hat{y}_{2}-d\right)-\frac{m}{m+p_{1}} \theta_{1} c
$$

Using (35), one can show that the derivative of $H$ with respect to $\theta_{1}$ has the same sign as:

$$
-q_{1}(1-\eta)(1-\alpha)\left(\hat{y}_{2}-d\right)
$$

As $\alpha<1$, the previous quantity is negative. This means that the left hand of equation (36) is an increasing function of parameter $\alpha$ ( $H$ grows with $\alpha)$. As it is decreasing function of $\theta_{2}$ (under (35) $H$ is positive), we deduce that an increase in $\alpha$ raises $\theta_{2}$. Consequently, the optimal value of $\theta_{2}$ is higher than its equilibrium value. This states the first part of the proposition.

We now turn to the educational effort $e$. Using the same reasoning as above, let us consider the optimality condition for $e$ (see equation (31). This equation can be rewritten as follows:

$$
E=\frac{p_{1}\left(y_{1}-d\right)-m \theta_{1} c}{m+p_{1}}-\frac{m}{m+\lambda}\left[\frac{p_{2}}{m+p_{2}}\left(y_{2}-d+\frac{\lambda}{m} H\right)-\frac{m+\lambda}{m+p_{2}} \theta_{2} c\right]-\frac{m}{\pi^{\prime}(e)}=0
$$

where the variables $p_{i}$ and $\theta_{i}$ (for $\left.i=1,2\right)$ as well as $H$ are deduced from equations (35) and (36).

For $\alpha=0$, the previous equation determines the equilibrium value of the educational effort $e$ whereas it determines the optimal value of $e$ for $\alpha=\alpha^{*}$.

Holding $H$ as a constant, the derivative of $E$ with respect to $\theta_{1}$ has the same sign as:

$$
(1-\eta) q_{1}\left(y_{1}-d\right)-\left(m+\eta p_{1}\right) c
$$

Using (35), one can see that this derivative is positive for $\alpha>0$. As $H$ is a decreasing function of $\theta_{1}$, we deduce that $E$ grows with $\theta_{1}$. 
On the other hand, one can show that the derivative of $E$ with respect to $\theta_{2}$ is proportional to:

$$
-q_{2}(1-\eta)\left(y_{2}-d+\frac{\lambda}{m} H\right)+\frac{m+\lambda}{m}\left(m+\eta p_{2}\right) c
$$

From (36), we deduce that the previous expression is nil.

As an increase in $\alpha$ lowers $\theta_{1}$, we thus obtain that $E$ is a decreasing function of $\alpha$. So the same holds for the ratio $\left(m / \pi^{\prime}(e)\right)$. As the function $\pi($.$) is concave, it results that e$ is a decreasing function of $\alpha$. This proves the second part of Proposition 2.

Q.E.D.

In line with our intuition, relative to a social optimum, $\theta_{2}$ is too low and $e$ is to high in a decentralized equilibrium.

\section{Optimal public policy}

The laissez-faire situation is not an optimum. What, then, should the Government do? We now present a self-financed Taxes and Subsidies Policy (TSP) leading to a social optimum. The same assumptions as above are adopted. The interest rate is equal to zero and the Hosios condition holds on both sub-markets.

\section{$5.1 \quad$ Taxing sector 1}

As previously highlighted job creation is too high in sub-market 1. The Government can decentralize the social optimum by implementing an appropriate fiscal policy. We now prove that in order to restore the efficiency, a tax $\tau$ could be levied in sub-market 1 . Thus, the value of a filled job $J_{1}$, verified by (3), now depends on $\tau$ :

$$
(r+m)\left(J_{1}-V_{1}\right)=y_{1}-\tau-w_{1}-(r+m) V_{1}
$$

By comparison between (8) and the optimal condition (29), we obtain that the tax would restore the sub-market efficiency as long as it is equal to:

$$
\tau=\frac{\hat{\ell}_{2}}{u_{1}+\hat{\ell}_{2}} \hat{y}_{2}+\frac{u_{1}}{u_{1}+\hat{\ell}_{2}} d-d=\frac{\hat{l}_{2}}{\hat{l}_{2}+u_{1}}\left(\hat{y}_{2}-d\right)>0
$$

Let $\alpha$ be the share of workers coming from sector 2 in the employment of sector 1 :

$$
\alpha=\frac{\hat{l}_{2}}{\hat{l}_{2}+u_{1}}
$$

The tax can therefore be written as:

$$
\tau=\alpha\left(\hat{y}_{2}-d\right)
$$

and $S_{1}$ is now given by: 


$$
S_{1}=\frac{y_{1}-\left(\alpha \hat{y}_{2}+(1-\alpha) d\right)}{m+\beta p_{1}}
$$

Therefore, sector-1 equilibrium (8) becomes:

$$
0=-c+q_{1}(1-\beta) \frac{y_{1}-\left(\alpha \hat{y}_{2}+(1-\alpha) d\right)}{m+\beta p_{1}}
$$

Equation (40) coincides with the optimality condition in sector 1 (29). With tax $\tau$, the high-skill job creation becomes partially efficient. In short the pigovian tax $\tau$ makes sector 1 firms internalize the real cost of hiring a worker that comes from sector 2. However, implementing this tax does not only restore partial efficiency in sector 1 , it also modifies efficiency results for sector 2 and for educational choices: job creation in sector 2 is no longer efficient and the same holds for the educational effort $e$.

These distortions lead to dedicate the tax $\tau$ to the funding of two compensatory transfers. The first one, denoted by $\sigma_{q}$ is allocated to sector 2 firms when their worker quit their low-skill job. The transfer $\sigma_{q}$ is given by:

$$
\sigma_{q}=\frac{\tau}{m}
$$

The second transfer, denoted by $\sigma_{e}$, is allocated to the (entrant) workers whose educational effort $e$ is successful. The transfer $\sigma_{e}$ is given by:

$$
\sigma_{e}=\frac{p_{1}}{m+p_{1}} \sigma_{q}
$$

Before showing that these transfers offset the distortions created by the tax $\tau$, we need to verify that the policy is self-financed. As there are $m \pi$ workers whose effort $e$ is successful and $p_{1} \hat{l}_{2}$ quits, Government's expenditures are equal to:

$$
m \pi \sigma_{e}+p_{1} \hat{l}_{2} \sigma_{q}=\left(\frac{m \pi}{m+p_{1}}+\hat{l}_{2}\right) p_{1} \sigma_{q}
$$

From equations (23), (24) and (41), we deduce that:

$$
\left(\frac{m \pi}{m+p_{1}}+\hat{l}_{2}\right) p_{1} \sigma_{q}=\left(u_{1}+\hat{l}_{2}\right) p_{1} \sigma_{q}=m l_{1} \sigma_{q}=l_{1} \tau
$$

As Government's receipts are given by $\left(l_{1} \tau\right)$ per period, this shows that the Government balanced budget constraint is satisfied for this self-financed TSP.

\subsection{Subsidizing Sector 2}

By restoring efficiency in sector 1, one has reduced job creation in sector 2 far beyond the efficiency level. In order to restore the efficiency in the overall labor market, we propose to subsidy sector 2 firms whose workers leave for sector 1 . With the compensatory transfer $\sigma_{q}$ (see equation (41)), the private surplus $S_{2}$ now satisfies (for $r=0$ ): 


$$
\frac{(m+\lambda)\left(m+\beta p_{2}\right)}{m} S_{2}=y_{2}-d+\lambda \frac{\hat{y}_{2}-d}{m+p_{1}}+\lambda \frac{p_{1}}{m+p_{1}} \sigma_{q}+\frac{\lambda}{m} \beta p_{1} S_{1}
$$

On the other hand, using equation (40) one can see that, with the tax, the quantity $\left(\beta p_{1} S_{1}\right)$ is now given by:

$$
\beta p_{1} S_{1}=\frac{p_{1}\left(y_{1}-d\right)-m \theta_{1} c}{m+p_{1}}-\frac{p_{1}}{m+p_{1}} m \sigma_{q}
$$

Combining the two previous equations yields:

$$
\frac{(m+\lambda)\left(m+\beta p_{2}\right)}{m} S_{2}=y_{2}-d+\lambda \frac{\hat{y}_{2}-d}{m+p_{1}}+\frac{\lambda}{m} \frac{p_{1}\left(y_{1}-d\right)-m \theta_{1} c}{m+p_{1}}
$$

Substituting $S_{2}$ into equation (19) shows that transfer $\sigma_{q}$ enables to restore the efficiency of the low-skill vacancy creation (see equation (30) for $\beta=\eta_{2}$ ).

\subsection{Rewarding educational success}

With the reward $\sigma_{e}$ defined by equation (42), the first order condition (21) has to be rewritten as follows (for $\mathrm{r}=0$ ):

$$
\begin{aligned}
& \pi^{\prime}(e)\left(U_{1}+\frac{p_{1}}{m+p_{1}} \sigma_{q}-U_{2}\right)-1=0 \\
& \pi^{\prime}(e)\left(\beta p_{1} S_{1}+\frac{p_{1}}{m+p_{1}} \sigma_{q}-\beta p_{2} S_{2}\right)=m
\end{aligned}
$$

Using equation (43), the previous equation can be rewritten as:

$$
\begin{aligned}
& \left(\frac{p_{1}}{m+p_{1}}\left(y_{1}-d\right)-\frac{m}{m+p_{1}} \theta_{1} c-\frac{p_{1}}{m+p_{1}} \sigma_{q}+\frac{p_{1}}{m+p_{1}} \sigma_{q}-\beta p_{2} S_{2}\right)-\frac{m}{\pi^{\prime}(e)}=0 \\
& \left(\frac{p_{1}}{m+p_{1}}\left(y_{1}-d\right)-\frac{m}{m+p_{1}} \theta_{1} c-\beta p_{2} S_{2}\right)-\frac{m}{\pi^{\prime}(e)}=0
\end{aligned}
$$

As the efficiency of $\theta_{2}$ is restored (despite the tax), $\beta p_{2} S_{2}$ remains equal to:

$$
\frac{m}{m+\lambda}\left[\frac{p_{2}}{m+p_{2}}\left(y_{2}-d+\lambda \hat{S}_{2}+\frac{\lambda \beta p_{1} S_{1}}{m}\right)-\frac{m+\lambda}{m+p_{2}} \theta_{2} c\right]
$$

At first glance, the idea of rewarding educational success might look counterintuitive as one could point out that educational effort is lower in a social optimum according to proposition 2. The reason for this is that without subsidies private educational choices are no longer efficient for the optimum value of sub-market tightness $\theta_{1}$ (computed with the $\operatorname{tax} \tau$ ). In the absence of a reward the return to education (the opportunity to get a better-paid job) would be too weak thus leading to a reduction in formal education. The reward enables to compensate for this effect.

The following proposition summarizes the above results:

Proposition 3. With the $\operatorname{TSP}\left(\tau ; \sigma_{e} ; \sigma_{q}\right)$ the decentralized equilibrium is a social optimum. 


\section{Conclusion}

In many countries, governments subsidize formal education and/or training through different channels. In this way, the first Clinton administration made skill upgrading a major priority. Are these subsidies justified?

We set up a model in which workers face a tradeoff between acquiring formal education (thus having the opportunity to obtain a good job directly) and learning by doing in a low-skill job, then searching (while on-the-job) for a high-skill job. We state that workers doesn't choose the right amount of formal education when faced to this tradeoff. Even if the decentralized equilibrium is partially efficient in terms of low-skill job creation and educational choices, it is inefficient in terms of high-skill job creation. Because high-skill job creation is too high and induces a hold up behavior which penalizes low-skill jobs, a tax have to be levied on high-skill firms. Therefore, the educational choices and lowskill job creation will not be partially efficient anymore. A self-financed Tax and Subsidy Policy restore the market efficiency. The tax should finances two compensatory transfers: a subsidy to low-skill job whose worker is trained and a reward aiming at encourage educational effort.

To conclude we would like to put the stress on an unexpected result of our study. Economists usually believe that education would not be high enough in the presence of search-frictions. Search-frictions create rents which implies that a part of return to education to go to firms. Therefore, the incentive of workers to invest in their formal education would be too low. We have shown that this widespread view may be incorrect. Without on-the-job search, educational choices are perfectly efficient despite search-frictions. The reason for this is that firms have to pay for the cost of creating the jobs that educated workers will hold. As already mentioned, in our setting the inefficiency of the education effort in the laissez-faire situation doesn't come from private education choices but from the presence of the hold up phenomenon. 


\section{References}

[1] Acemoglu, D., 2002. Technical Change, Inequality, and The Labor Market, Journal of Economic Literature 40, 7-72.

[2] Acemoglu, D. and J.S. Piscke, 1999. Beyond Becker: Training in Imperfect Labor Markets, Economic Journal 109, 112-142.

[3] Adda, J., Dustmann, C., Meghir, C., and J-M. Robin, 2006. Career Progression and Formal versus On-the-Job Training, IZA Discussion Paper No.2260.

[4] Arrow, K., 1962. The Economic Implications of Learning by Doing, Review of Economic Studies 29(3), 155-173.

[5] Becker, G., 1975. Human capital, second edition, Chicago: The University of Chicago Press.

[6] Ben-Porath, Y., 1967. The Production of Human Capital and the Life Cycle of Earnings, Journal of Political Economy 75(4), 352-365.

[7] Charlot, O. and B. Decreuze, 2005. Self-selection in education with matching frictions, Labour Economics 12, 251-267.

[8] Charlot, O. and B. Decreuze, 2007. Over-education for the rich, under-education for the poor: a search-theoretic microfoundation, MPRA Paper No. 3624.

[9] Heckman, J., Lochner L. and R. Cossa, 2002.Learning-By-Doing Vs. On-the-Job Training: Using Variation Induced by the EITC to Distinguish Between Models of Skill Formation, NBER Working Paper No.W9083.

[10] Hosios, A., 1990. On the Efficiency of Matching and Related Models of Search and Unemployment, Review of Economic Studies 57(2), 279-298.

[11] Killingsworth, M, 1982."Learning by Doing" and "Investment in Training": A Synthesis of Two "Rival" Models of the Life Cycle, Review of Economic Studies 49(2), 263-71.

[12] Lechthaler, W. and D. Snower, 2007. Institutions and Training Inequality, Kiel Working Papers 1372, Kiel Institute for the World Economy.

[13] Machin, S., 1995. Changes in the Relative Demand for Skills in the UK Labour Market, CEP Discussion Papers 0221, Centre for Economic Performance, LSE. (in "Acquiring Skills" by Alison L. Booth, Dennis J. Snower, Centre for Economic Policy Research (Great Britain), New York : Cambridge University Press, 1996.)

[14] Mincer, J., 1994. Investment in U.S. Education and Training, NBER Working Paper No.4844. 
[15] Mincer, J., 2003. Technology and the Labor Market, Review of Economics of the Household 1(4), 249-272.

[16] Moen, E., 1999. Education, Ranking, and Competition for Jobs, Journal of Labor Economics 17(4), 694-723.

[17] Moscarini, G. and F. Vella, 2008. Occupational Mobility and the Business Cycle, NBER Working Paper No.13819.

[18] Pigou, A. C.,1912. Wealth and welfare, London: Macmillan.

[19] Pissarides, C., 2000. Equilibrium Unemployment Theory, second edition, MIT Press, Cambridge, MA. 